\title{
Thoracoabdominal mechanics during tidal breathing in normal subjects and in emphysema and fibrosing alveolitis
}

\author{
NJ BRENNAN, AJR MORRIS, MALCOLM GREEN
}

From Brompton Hospital, London

ABSTRACT Thoracoabdominal motion and intrathoracic (oesophageal), intra-abdominal (gastric), $\stackrel{\substack{\infty \\ \rightarrow}}{\infty}$ and transdiaphragmatic pressures were measured during tidal breathing in 20 erect ${ }_{\mathrm{N}}$ subjects-six normal, seven, with emphysema, and seven with fibrosing alveolitis. In normal o subjects all diameters increased synchronously during inspiration and were accompanied by rises in abdominal and transdiaphragmatic pressures. Five patients with fibrosing alveolitis showed a reduction in upper ribcage motion, but normal lower ribcage and abdominal motion; stiff fibrotic lungs may sometimes impair the ability of the diaphragm to expand the upper ribcage and result in proportionally more expansion of the bases. Four emphysematous patients showed increased anteroposterior motion of the ribcage and four showed paradoxical inward motion of the lower ribcage during inspiration. These changes apparently result from increased activity of intercostal and accessory muscles and altered configuration of the diaphragm. The muscles of patients with large, overinflated lungs are at a greater disadvantage than those with small fibrosed lungs.

Konno and $\mathrm{Mead}^{1}$ analysed the relative contributions of the ribcage and of the abdomen and diaphragm to ventilation in normal subjects. Several authors have applied similar techniques to patients with severe chronic airways obstruction, ${ }^{2-4}$ but most groups have studied patients supine and during a variety of contrived respiratory manoeuvres. ${ }^{45}$ Changes in posture from erect to supine affect both static chest wall configuration and its pattern of movement in normal ${ }^{6}$ and emphysematous subjects. ${ }^{4}$ We therefore studied normal subjects during tidal breathing in the erect position, since this is the usual posture during daily activities. For comparison we also investigated patients with emphysema (and large lungs) and patients with fibrosing alveolitis (and small lungs). There do not appear to have been any previous studies of patients with fibrotic lung disease.

\section{Methods}

The normal subjects were healthy volunteers. Patients in the emphysema group were selected on the basis of clinical history and findings at clinical examination, a compatible chest radiograph, and

Reprints will not be available. lung function test values showing hyperinflation with $\stackrel{\odot}{\varnothing}$ low carbon monoxide transfer coefficient (KCO) $\overrightarrow{\vec{P}}$ (table 1). The patients with fibrosing alveolitis had been diagnosed histologically by lung biopsy. Although the vital capacities of patients with emphysema and fibrosing alveolitis were similar, total lung capacity was nearly twice as great in the emphysema group. KCO was low in both groups. Lung volumes were measured by body plethysmograph and $\mathrm{KCO}$ by a helium dilution Resparameter (PK Morgan, Chatham). All patients were ambulat- \&े ory and they were not in the convalescent phase of an acute infection. Informed consent was obtained.

Table 1 Lung function data for the three groups: mean $( \pm S E)$ of percentage predicted for each subject ${ }^{7}$

\begin{tabular}{llll}
\hline & $\begin{array}{l}\text { Normal } \\
(n=6)\end{array}$ & $\begin{array}{l}\text { Fibrosing } \\
\text { alveolitis } \\
(n=7)\end{array}$ & $\begin{array}{l}\text { Emphysema } \\
(n=7)\end{array}$ \\
\hline FVC & $109 \pm 3.6$ & $74 \pm 5.2$ & $73 \pm 5.9$ \\
FEV & $104 \pm 4.8$ & $75 \pm 6.8$ & $30 \pm 3.4$ \\
TLC & $112 \pm 6.6$ & $68 \pm 4.2$ & $131 \pm 6.4$ \\
FRC & $118 \pm 12.7$ & $66 \pm 5.7$ & $165 \pm 7.1$ \\
RV & $128 \pm 13.7$ & $66 \pm 5.9$ & $220 \pm 14.7$ \\
KCO & $102 \pm 5 \cdot 1$ & $61 \pm 7.3$ & $43 \pm 3.7$ \\
\hline
\end{tabular}

FVC-forced vital capacity; FEV - forced expiratory volume in $\Omega$ one second; TLC -total lung capacity; FRC - functional residual $\mathbb{D}$ 62 
Thoracoabdominal motion was studied in four diameters with linearised magnetometers attached to the skin with double-surface adhesive tape. ${ }^{8}$ Changes in the anteroposterior diameter of the ribcage $\left(R-C_{2-p}\right)$ were measured in the midline $2 \mathrm{~cm}$ above the level of the xiphisternal junction, and the a-p diameter of the abdomen $\left(\mathrm{ABD}_{\mathrm{a}-\mathrm{p}}\right)$ in the midline $2 \mathrm{~cm}$ above the umbilicus. Changes in ribcage high lateral $\left(\mathrm{R}-\mathrm{C}_{\mathrm{h}-1}\right)$ and low lateral $\left(\mathrm{R}-\mathrm{C}_{\mathrm{H}-1}\right)$ diameters were recorded in the mid-axillary line at the level of the xiphisternal junction and the lower costal margin respectively. The $\mathrm{R}-\mathrm{C}_{\mathrm{H}}$ position was selected because of its proximity to the insertion of the diaphragm. It predominantly spans the abdominal cavity rather than the thorax in normal people. To minimise artefacts due to skin movements, the subjects leaned against a board inclined $17^{\circ}$ backwards from vertical, their arms supported away from the chest wall by rests. They were instructed to maintain a constant posture throughout the experiment.

Changes in lung volume were measured at the mouth with an Ohio 840 spirometer. Oesophageal $\left(P_{\text {oes }}\right)$ and gastric $\left(P_{g}\right)$ pressures were measured with balloons passed into the appropriate positions, standard techniques being used. ${ }^{9}$ Both pressures were measured in relation to atmospheric pressure by identical pressure transducers (Mercury $M_{2} / 555$ ). Transdiaphragmatic pressure $\left(\mathrm{P}_{\mathrm{di}}\right)$ was derived by electrically subtracting the signal of $P_{\text {oes }}$ from $P_{g}$ and was defined as zero at end-expiratory level during quiet breathing - that is, at functional residual capacity (FRC). Signals from the four magnetometers, volume change, $P_{\text {oes }}$, and $P_{g}$ were recorded on a magnetic tape multichannel recorder (Racal Store 7) and later displayed against time on a Mingograf 800 recorder or when required on an $\mathrm{X}-\mathrm{Y}$ recorder. Significance was tested by Student's $t$ test.

Each subject was asked to breathe quietly through the mouthpiece of the spirometer. Four consecutive breaths were analysed after the subjects had become thoroughly accustomed to the apparatus. In each subject means were taken of tidal volume (VT) and diameter change, and the mean of diameter change per litre of inspired volume in each breath was calculated.

\section{Results}

\section{Normal subjects}

Inspiration from FRC was associated with increase in all chest wall diameters, reaching a maximum at peak tidal inspiration and then returning to the FRC position (fig 1). The relationship between volume and diameter changes was nearly linear and there

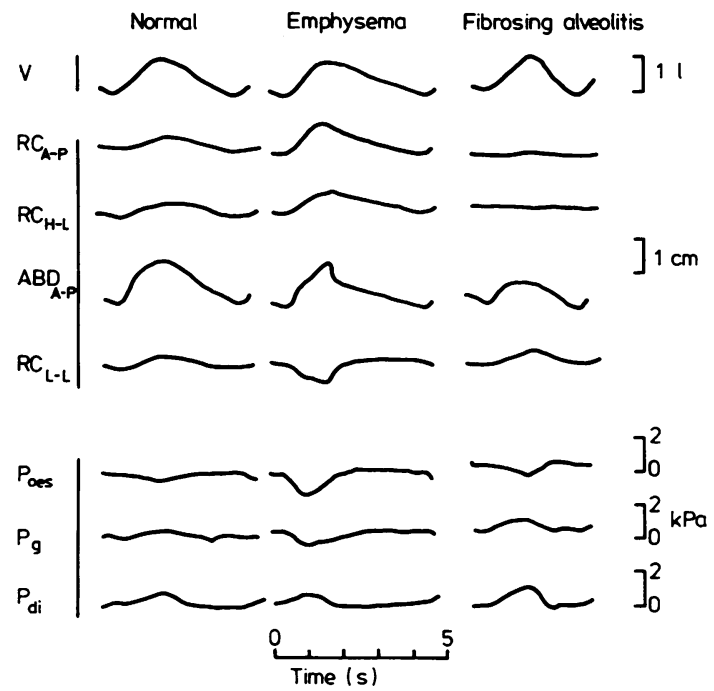

Fig 1 Simultaneous time tracings of inspired volume, ribcage diameter and pressure changes in three subjects, one from each group. Inspiration, increase in diameter, and rise in pressure are shown by upward deflection. $V$-change in volume; $R-C_{a-p}$-antero-posterior motion of ribcage; $R-C_{h-1}$-lateral motion of upper chest; $A B D_{a-p}$ -anteroposterior motion of abdomen; $R-C_{l-}-p$ lateral motion of lower chest; $\boldsymbol{P}_{\text {oes }}$-oesophageal pressure; $P_{R}$-intragastric pressure; $\boldsymbol{P}_{d-\text { transdiaphragmatic }}$ pressure. The patient with fibrosing alveolitis shows reduced $R-C_{a-p}$ and $R-C_{h-l}$ motion; the emphysematous patient shows increased $R-C_{a-p}$ motion, paradoxical $R-C_{l-l}$ motion, and a fall in $P_{g}$ during inspiration.

was little difference between inspiration and expiration (fig 2). During inspiration $P_{\text {oes }}$ fell while $P_{g}$ and $P_{\mathrm{di}}$ rose; the opposite occurred during expiration (fig 1). $P_{d i}$ was zero for roughly the second half of expiration.

\section{Fibrosing alveolitis}

In patients with fibrosing alveolitis VT did not significantly differ from the values in normal subjects. In three subjects expansion of $R-C_{a-p}$ and $R-C_{h-1}$ was minimal and in two further subjects one of these was substantially reduced. By contrast, $R-C_{1-1}$ and $A B D_{a-p}$ diameters changed normally in all (fig 1). At a given lung volume there were only small differences in chest wall diameters between inspiration and expiration (fig 2). The patterns of changes in $P_{\text {oes }}, P_{g}$, and $P_{d i}$ were similar to those in normal subjects (fig 1 ).

\section{Emphysema}

There were appreciable abnormalities of motion in patients with emphysema (fig 3 and table 2). $R-C_{a-p}$ motion was greater than in normal subjects and much greater than in fibrosing alveolitis. Subjects 


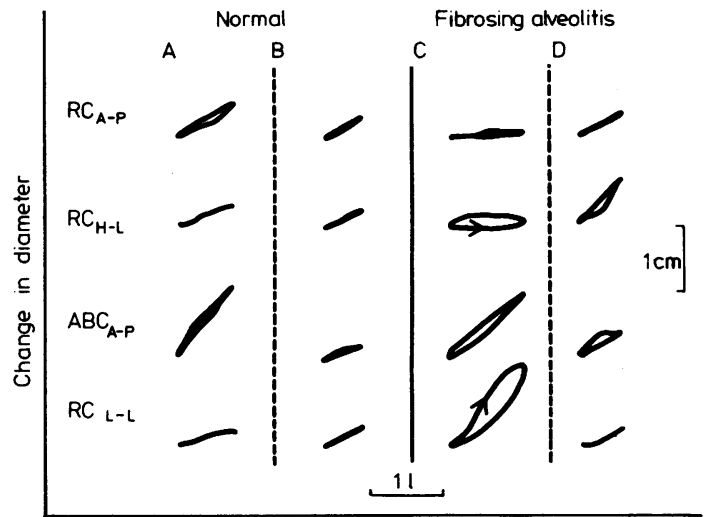

Fig 2 Change in chest wall diameters against lung volume in two normal subjects $(A, B)$ and two patients with fibrosing alveolitis $(C, D)$. In the fibrosing alveolitis group three patients showed a pattern similar to that of subject $C$, with reduced $R-C_{a-p}$ and $R-C_{h-l}$ motion; subject $D$ and the other two subjects showed normal motion. (Abbreviations as in fig 1.)

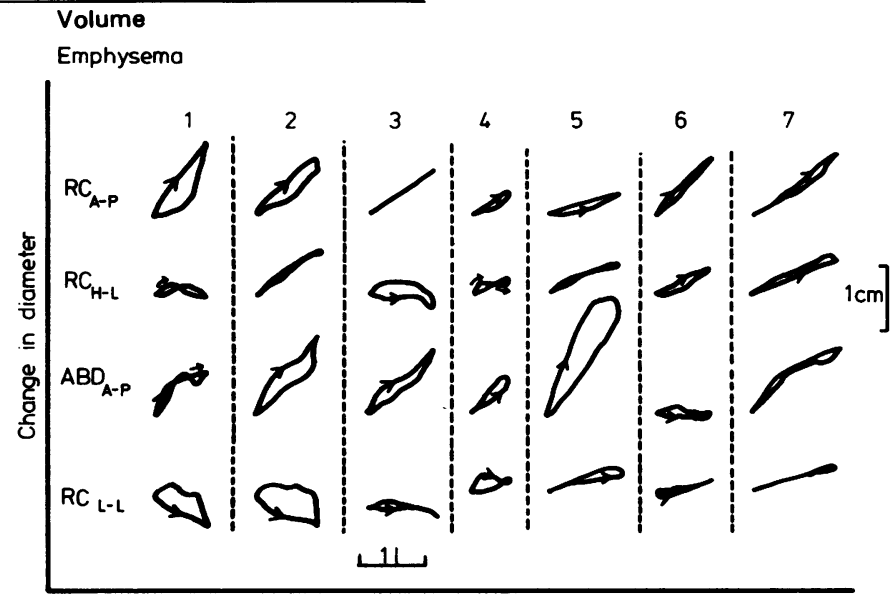

Volume

Fig 3 Plot of change in chest wall diameter against volume in the seven emphysematous patients to show different patterns. The arrow indicates inspiratory phase. Subject 2 is the same patient as in figure 1. Increased $R-C_{a-p}$ motion is seen in subjects 1-3 and paradoxical $R-C_{l-l}$ motion in subjects 1-4. Subject 5 shows increased and subject 6 decreased abdominal motion while subject 7 shows relatively normal motions. (Abbreviations as in fig 1.)

Table 2 Mean values ( $\pm S E$ ) for tidal volume $(V T)$ and for increase of chest wall diameters between end-expiration (FRC) and end-inspiration $(V T)$, and chest wall diameters expressed as $\mathrm{cm} / \mathrm{l}$ of $V T$ for each subject (to allow for differences in $V T$ between subjects)

\begin{tabular}{|c|c|c|c|c|}
\hline$V T(m l)$ & $R-C_{a-p}(\mathrm{~cm})$ & $R-C_{h-l}(\mathrm{~cm})$ & $R-C_{l-l}(\mathrm{~cm})$ & $A B D_{a-p}(\mathrm{~cm})$ \\
\hline $\begin{array}{lr}\text { Normal } & 774 \pm 223 \\
\text { Fibrosing alveolitis } & 975 \pm 288 \\
\text { Emphysema } & 1009 \pm 290\end{array}$ & $\begin{array}{l}0 \cdot 36 \pm 0 \cdot 15 \\
0 \cdot 23 \pm 0 \cdot 13 \\
0.80 \pm 0 \cdot 31^{* *} \\
(\mathrm{~cm} / \mathrm{l})\end{array}$ & $\begin{array}{l}0.30 \pm 0.12 \\
0.27 \pm 0.35 \\
0.26 \pm 0.39 \\
(\mathrm{~cm} / \mathrm{l})\end{array}$ & $\begin{aligned} 0.40 & \pm 0.20 \\
0.66 & \pm 0.49 \\
-0.09 & \pm 0.41^{*} \\
(\mathrm{~cm} / \mathrm{l}) & \end{aligned}$ & $\begin{array}{l}0.72 \pm 0.37 \\
0.61 \pm 0.56 \\
0.84 \pm 0.57 \\
(\mathrm{~cm} / \mathrm{l})\end{array}$ \\
\hline $\begin{array}{l}\text { Normal } \\
\text { Fibrosing alveolitis } \\
\text { Emphysema }\end{array}$ & $\begin{array}{l}0.49 \pm 0.19 \\
0.27 \pm 0.20 \\
0.84 \pm 0.37^{*}\end{array}$ & $\begin{array}{l}0.39 \pm 0.14 \\
0.36 \pm 0.50 \\
0.27 \pm 0.31\end{array}$ & $\begin{array}{r}0.51 \pm 0.18 \\
0.67 \pm 0.38 \\
-0.10 \pm 0.46^{*}\end{array}$ & $\begin{array}{l}0.89 \pm 0.31 \\
0.58 \pm 0.39 \\
0.81 \pm 0.46\end{array}$ \\
\hline
\end{tabular}

${ }^{*} p<0.05 ;{ }^{* *} p<0.01$ compared with normal subjects.

Abbreviations as in figure 1 . 
(fig 3) showed paradoxical decrease in $\mathrm{R}-\mathrm{C}_{\mathrm{H}}$ and in two (subjects 1 and 3 ) there was also paradoxical change of $\mathrm{R}-\mathrm{C}_{\mathrm{h}-1}$ diameter, most noticeable near peak inspiration. Abnormal patterns of $A_{B D}$ motion were seen in two (subjects 1 and 6), and in three (subjects $2,3,5) \mathrm{ABD}_{\mathrm{a}-\mathrm{p}}$ diameter was much smaller during expiration than during inspiration at the same lung volume. These abnormalities of chest wall motion did not correlate with lung function values, although the two subjects ( 1 and 2 ) with the most evident abnormalities in ribcage motion were the most severely affected by dyspnoea.

During inspiration $P_{\text {oes }}$ fell but $P_{g}$ was variable: it usually fell slightly but in some subjects remained unchanged or rose.

\section{Discussion}

It has previously been shown that during quiet tidal breathing in erect normal subjects the ribcage and abdominal wall move along their relaxation pressure-volume (p-v) curve. ${ }^{10}$ Similarly, the relationship between abdominal pressure and both ribcage and abdominal motion are the same during tidal breathing as during relaxation from total lung capacity. Since the ribcage and abdominal components of the chest wall behave as though relaxed, it has been suggested that the diaphragm is the only important contracting muscle during quiet breathing, and thus minimal energy is needed to expand the chest wall. ${ }^{10}{ }^{11}$ Our results in normal subjects are compatible with this analysis. In fibrosing alveolitis, however, we found that movement of the upper ribcage was reduced in five out of seven patients. In emphysema the patterns were varied and disorganised.

In fibrosing alveolitis the reduced lung volume tends to cause the diaphragm to be lengthened and highly curved. This would place the muscle at a mechanical advantage. ${ }^{12} 13$ Recent work has shown that diaphragmatic activity produces greater pleural pressure swings near the bases than at the lung apices in dogs, ${ }^{14}$ and there is evidence of similar pressure gradients in normal man, which may affect ventilation distribution..$^{15}$ The decreased pulmonary compliance in fibrosing alveolitis may exacerbate these pressure gradients down the lungs and accentuate the normal top-to-bottom ventilation gradient. Preferential ventilation of the lung bases could explain the clinical observation that crepitations are maximal in this zone.

It is well recognised that in emphysema there is increased activity of the intercostals and accessory muscles of respiration, ${ }^{16}$ and consequently these patients show a relatively larger contribution of ribcage displacement to ventilation than normal sub- jects. ${ }^{24}$ Such activity presumably distorts the chest wall from its relaxation p-v curve, thus increasing the work of breathing. ${ }^{111718}$ Furthermore, abnormal patterns of abdominal wall motion have been described in patients with chronic airways obstruction, particularly when supine. ${ }^{45}$ Our emphysematous patients did show features compatible with excessive activity of intercostal and accessory muscles during inspiration: increased amplitude of $\mathrm{R}-\mathrm{C}_{\mathrm{a}-\mathrm{p}}$ excursions and little change or a fall in $\mathrm{P}_{\mathrm{g}}{ }^{19}$ The latter is presumably due to ribcage elevation by muscles other than the diaphragm. In addition, in some individuals $\mathrm{ABD}_{\mathrm{a}-\mathrm{p}}$ diameter during expiration was smaller than during inspiration at the same lung volume. This implies activity of abdominal muscles during expiration. Conceivably such activity may aid diaphragmatic function by exerting an upward force to increase diaphragm length and curvature before the next inspiration.

Some of our emphysematous patients had paradoxical inward motion of the lower ribcage during inspiration. Clinically this has been called Hoover's $\operatorname{sign}^{20}$ and is thought to result from inward tension exerted by the flattened diaphragm. ${ }^{216}$ In addition, the flat diaphragm exposes the lower ribcage to negative intrapleural pressure generated by both diaphragm and the overactive intercostal and accessory muscles, whereas in normal subjects the presence of an area of apposition between diaphragm and ribcage means that the lower ribcage is effectively exposed to a positive outward, intraabdominal pressure during inspiration. The mobility of these lowermost "floating" ribs may cause them to deform easily in response to such changes in the forces acting on them.

We conclude that emphysema leads to disorganised and apparently inefficient movement, even during tidal breathing. Whether training such patients to breathe with a pattern more similar to that of normal people is practicable or useful remains to be established, perhaps by studies such as these before and after training. In fibrosing alveolitis expansion of the upper part of the lungs appears to be impaired despite an increase in the mechanical advantage of the diaphragm. This may be due to the stiffness of the lungs and might explain basal crepitations and, in part, the reduction of gas transfer. Conceivably muscle training in these subjects should be directed, if at all, to their upper ribcages.

\section{References}

${ }^{1}$ Konno K, Mead J. Measurement of the separate volume changes of the ribcage and abdomen during breathing. J Appl Physiol 1967;22:407-22. 
${ }^{2}$ Marazzini L, Rizzato GF. Relative contribution of the ribcage and abdomen-diaphragm to the variation of lung volume in emphysema. Respiration 1970;27:105-19.

${ }^{3}$ Sharp JT, Danon J, Druz WS, Goldberg NB, Fishman H, Machnach W. Respiratory muscle function in patients with chronic obstructive pulmonary disease: its relationship to disability and respiratory therapy. Am Rev Respir Dis 1974;110 (No 6, part 2):154-67.

${ }^{4}$ Sharp JT, Goldberg NB, Druz WS, Fishman HC, Danon J. Thoraco-abdominal motion in chronic obstructive pulmonary disease. Am Rev Respir Dis 1977;115:47-56.

5 Ashutosh K, Gilbert R, Auchinloss JH, Peppi D. Asynchronous breathing movements in patients with chronic obstructive pulmonary disease. Chest 1975;67:553-7.

- Vellody VP, Nassery M, Druz WS, Sharp JT. Effects of body position change on thoraco-abdominal motion. $J$ Appl Physiol 1978;45:581-9.

${ }^{7}$ Cotes JE. Lung function: asessment and application in medicine. 4th ed. Oxford: Blackwell Scientific Publications, 1979.

${ }^{8}$ Mead J, Peterson N, Grimby G. Pulmonary ventilation measured from body surface movements. Science 1967;156:1383-4.

${ }^{9}$ Milic-Emili J, Mead J, Turner JM, Glauser EM. Improved technique for estimating pleural pressure from esophageal balloons. J Appl Physiol 1964;19:207-11.

${ }^{10}$ Goldman MD, Mead J. Mechanical interaction between the diaphragm and ribcage. J Appl Physiol
1973;35:197-204.

${ }^{11}$ Grimby G, Goldman M, Mead J. Respiratory muscle action inferred from ribcage and abdominal V P parti- $S$ tioning. J Appl Physiol 1976;41:739-51.

12 Marshall R. Relationships between stimulus and work of $\frac{}{0}$ breathing at different lung volumes. J Appl Physiol $\overline{\widehat{A}}$ 1962;17:917-21.

${ }^{13}$ Green M, Mead J, Sears TA. Muscle activity during chest wall restriction and positive pressure breathing in man. Respir Physiol 1978;35:283-300.

${ }^{14}$ D'Angelo E, Sant'Ambrogio G, Agostoni E. Effect of $\vec{\odot}$ diaphragm activity or paralysis on distribution of $\vec{A}$ pleural pressure. J Appl Physiol 1974;37:311-5.

15 Roussos CS, Fixley M, Genest J, Cosio M, Kelly S, Martin RR, Engel LA. Voluntary factors influencing the distribution of inspired gas. Am Rev Respir Dis w 1977;116:457-67.

${ }^{16}$ Cambell EJM. Physical signs of diffuse airways obstruc- $\overrightarrow{0}$ tion and lung distension. Thorax 1969;24:1-3.

${ }^{17}$ Konno K, Mead J. Static volume-pressure characteristics 응 of the ribcage and abdomen. J Appl Physiol 1968;24:544-8.

${ }^{18}$ Goldman MD, Grimby G, Mead J. Mechanical work of breathing derived from ribcage and abdominal V-P partitioning. J Appl Physiol 1976;41:752-63.

19 Druz WS, Danon J, Fishman HC, Goldberg NB, Moisan TC, Sharp JT. Approaches to assessing respiratory $\vec{\emptyset}$ muscle function in respiratory disease. Am Rev Respir Dis 1979;119 (No 2, part 2):145-9.

${ }^{20}$ Hoover CF. Definitive percussion and inspection in estimating size and contour of the heart. JAMA 1920;75:1626-31. 